\title{
Clinical Study \\ Serum Level of the Angiotensin-Converting Enzyme in Patients with Idiopathic Acute Optic Neuritis: A Case-Control Study
}

\author{
Heshmatollah Ghanbari, ${ }_{1}^{1}$ Alireza Dehghani, ${ }^{1}$ Awat Feizi $\left(\mathbb{D},{ }^{2}\right.$ Arman Amirkhani, \\ and Mohsen Pourazizi iD ${ }^{1}$ \\ ${ }^{1}$ Isfahan Eye Research Center, Department of Ophthalmology, Isfahan University of Medical Sciences, Isfahan, Iran \\ ${ }^{2}$ Department of Biostatistics and Epidemiology, School of Health, Isfahan University of Medical Sciences, Isfahan, Iran
}

Correspondence should be addressed to Mohsen Pourazizi; m.pourazizi@yahoo.com

Received 10 January 2020; Revised 17 February 2020; Accepted 2 March 2020; Published 31 March 2020

Academic Editor: Lucio Tremolizzo

Copyright (C) 2020 Heshmatollah Ghanbari et al. This is an open access article distributed under the Creative Commons Attribution License, which permits unrestricted use, distribution, and reproduction in any medium, provided the original work is properly cited.

\begin{abstract}
Purpose. To evaluate the serum level of angiotensin-converting enzyme (ACE) as an important component of the reninangiotensin system (RAS) in optic neuritis (ON) compared to the healthy control group in the context investigating the possible role of ACE in ON pathogenesis. Methods. This case-control study was conducted on patients with ON and healthy controls. Serum ACE levels were assessed and compared between the two groups by using commercially available kits by ELISA for ACE. Results. Sixty-five ON patients (75.4\% female, mean age $29.70 \pm 8.30$ years) and 65 controls ( $75.4 \%$ female, mean age $29.66 \pm 8.36$ years) were enrolled. The median serum ACE levels were $33.5 \mathrm{U} / \mathrm{L}$ (range: $25-540$ ) and $26 \mathrm{U} / \mathrm{L}$ (range: $22.3-72$ ) for the ON patients and controls, respectively. Serum ACE levels were significantly higher in the patients than in the control group $(P<0.001)$. High level of serum ACE (defined as a serum ACE $>65 \mathrm{U} / \mathrm{L})$ was present in $9(13.8 \%)$ patients with ON and $2(3.1 \%)$ controls. Conclusion. Our results indicated that the serum level of ACE appeared to be significantly higher in acute ON than in normal controls.
\end{abstract}

\section{Introduction}

Idiopathic acute optic neuritis $(\mathrm{ON})$ is manifested as unilateral subacute painful visual loss without any systemic or other neurological symptoms $[1,2]$. The etiology of $\mathrm{ON}$ varies, including infections, inflammation, exposure to toxins, and genetic disorders. In most cases, the responsible etiology may not be known for $\mathrm{ON}$, and in this case, it is termed idiopathic ON. In some cases, ON can also be associated with demyelinating disorders of the central nervous system (CNS), including multiple sclerosis (MS) or neuromyelitis optica (NMO) [3-5].

Angiotensin-converting enzyme (ACE) catalyzes the conversion of angiotensin I to angiotensin II. Although, there are no data on the assessment of serum ACE level in ON, systemic or local ACE levels have been investigated in various inflammatory conditions such as MS, sarcoidosis, rheumatoid arthritis, diabetes mellitus, and viral encephalitis [6-8] There is increasing evidence supporting a potential role for the renin-angiotensin system (RAS) in inflammatory diseases, and it has considerable physiological significance in CNS. All RAS components, including ACE, are present in the mammalian brain [9]. A previous study has reported an RAS alternation in neural differentiation and several pathologic conditions such as MS $[10,11]$

The idea of measuring serum ACE levels in ON is associated with studies investigating the role played by RAS axis and angiotensin in autoimmune and inflammatory diseases [12-15]. In some studies, RAS and related factors such as angiotensin I, angiotensin II, and serum ACE were claimed to be one of the key elements affecting and regulating inflammatory responses in the brain [16]. 
In the current study, we evaluate the serum ACE level in ON patients based on the following hypothesis: on the one hand, $\mathrm{ON}$ is an immunologically mediated central nervous system disease and on the other hand, ACE activity may be involved in its pathogenesis of the inflammatory process; therefore, measurement of serum ACE levels can be included as a screening test in the initial evaluation of patients suspected of having ON [17].

The present study aimed to evaluate the serum ACE level in idiopathic acute $\mathrm{ON}$ patients than in healthy controls in order to demonstrate a possible role of RAS in the pathogenesis of $\mathrm{ON}$. We also aimed to determine the correlation of the ACE level with ON patients' characteristics.

\section{Materials and Methods}

This case-control study was conducted in patients with idiopathic acute $\mathrm{ON}$ and healthy controls in the ophthalmology department of the tertiary referral center affiliated with Isfahan University of Medical Sciences, Isfahan, Iran. The study population included ON patients with the first attack aged between 18 and 45 years. The healthy control group was equivalent to the patient group regarding age and gender, and it was selected from healthy subjects as candidates for refractive surgery who had no acute and chronic health problems or drug use history. The study was conducted in accordance with the guidelines of the Helsinki Declaration, and written informed consent was obtained from each subject before initiation of the study.

Some of the patients with conditions that might affect the serum ACE level were excluded from the study. These conditions were hypertension; receiving any drugs potentially interacting with the RAS system such as ACE inhibitors; diabetes mellitus; any renal parenchymal diseases; sarcoidosis; concomitant chronic liver disorders; and moderate or severe cardiopulmonary problems. Also, we excluded subjects if they had been diagnosed previously with MS or NMO, another cause of optic neuropathy, secondary causes of optic neuritis, or disc swelling (e.g., compressive optic neuropathies, infection, ischemic neuropathies, and toxic neuropathies).

The diagnosis of optic neuritis was clinically set with the typical signs of optic nerve dysfunction, including a history of unilateral sudden loss of vision, presence of relative afferent pupillary defect (RAPD) or defect on Humphrey visual field screening, color vision impairment, painful extraocular movements, and with or without the presence of disc swelling. All subjects were visited thorough ocular and systemic physical examination. Another cause of optic neuropathy, secondary causes of optic neuritis or disc swelling were excluded.

All patients underwent a completed ophthalmological examination, including assessment of detailed history, bestcorrected visual acuity (BCVA), RAPD response, color vision (with Ishihara plates), extraocular movements, and intraocular pressure (by application tonometry), in addition to a dilated funduscopic examination (with $78 \mathrm{D}$ lens) and an anterior segment examination (with slit lamp).
To evaluate the serum ACE level, $5 \mathrm{cc}$ venous blood of each participant was drawn from the cubital vein. The coagulated blood samples were centrifuged to collect the serum. Then, the sera were frozen at $-20^{\circ} \mathrm{C}$. After gathering all samples, we refer them to our special laboratory to measure the ACE level. ACE concentrations in the serum were measured by established enzyme-linked immunosorbent assay (ELISA) systems for ACE (R\&D Systems, Minneapolis, Minnesota, USA). Serum ACE levels were obtained from healthy controls using the same method as for the $\mathrm{ON}$ patient group. The normal reference range of ACE for the laboratory is 8-65 units for more than 14 years of age.

Continuous variables are reported as means with standard deviation (SD) or as medians with ranges. Independent samples $t$-test was applied to compare the means of continuous variables. For continuous variables with skewed distributions, the Mann-Whitney $U$ test was applied. Statistically significant differences were analyzed by the chisquare test for categorical variables. Snellen BCVA was transformed into a logarithm of the minimum angle of resolution (LogMAR). The association between serum ACE level and BCVA LogMAR was assessed using Spearman's correlation test. All statistical analyses were conducted using the Statistical Package for Social Sciences (SPSS) version 20 software (IBM Inc., Chicago, IL, USA), and $P<0.05$ was considered statistically significant.

\section{Results}

Sixty-five patients with $\mathrm{ON}$ and 65 control subjects were enrolled in the present study. There were 16 men $(24.6 \%)$ and 49 women $(75.4 \%)$ in each group. The mean age of patients with $\mathrm{ON}$ and controls was $29.70 \pm 8.30$ and $29.66 \pm 8.36$, respectively. There were no statistically significant differences between the ages of the study participants $(P=0.98)$. Table 1 presents a summary of demographic and clinical findings of $\mathrm{ON}$ patients according to sex distribution.

The median serum ACE levels were $33.5 \mathrm{U} / \mathrm{L}$ (range: 25-540) and $26 \mathrm{U} / \mathrm{L}$ (range: 22.3-72) for the ON patients and controls, respectively. Serum ACE levels were significantly higher in the $\mathrm{ON}$ patients than in the control group $(P<0.001)$ (Figure 1).

The median serum prolactin levels were $33.5 \mathrm{U} / \mathrm{L}$ (range: 29.10-540) in males and 33.5 U/L (range: 25.9-509.6) in females in $\mathrm{ON}$ patients. There was no significant difference in the serum ACE between male and female patients $(P=0.77)$.

High level of serum ACE (defined as a serum ACE >65 $\mathrm{U} / \mathrm{L})$ was present in $9(13.8 \%)$ patients with $\mathrm{ON}$ and $2(3.1 \%)$ controls $(P=0.02)$ (Figure 2$)$.

In $\mathrm{ON}$ patients, serum ACE was significantly higher in patients with better visual acuity $(P=0.03)$. Serum ACE did not vary significantly with sex, laterality of affected eye, RAPD score, and disc swelling (Table 2).

This study showed no significant relationship between the age and the serum ACE level of patients (Spearman correlation test, $\rho=-0.13$ and $P=0.30)$. In addition, a 
TABLE 1: Demographics and clinical findings in the idiopathic acute ON group.

\begin{tabular}{|c|c|c|c|c|}
\hline Characteristic & Total $(n=65)$ & Male $(n=16)$ & Female $(n=49)$ & $P$ value \\
\hline $\begin{array}{l}\text { Age (years) } \\
\text { Mean (SD) } \\
\text { Median (min-max) }\end{array}$ & $\begin{array}{c}29.70(8.30) \\
28(14-49)\end{array}$ & $\begin{array}{l}29.37(4.95) \\
29.5(18-37)\end{array}$ & $\begin{array}{c}29.80(9.18) \\
28(14-49)\end{array}$ & $0.81^{*}$ \\
\hline $\begin{array}{l}\text { Affected eye, } n(\%) \\
\text { Right } \\
\text { Left } \\
\end{array}$ & $\begin{array}{l}31(47.7) \\
34(52.3) \\
\end{array}$ & $\begin{array}{c}6(19.4) \\
10(80.6) \\
\end{array}$ & $\begin{array}{l}25(51) \\
24(49) \\
\end{array}$ & $0.34^{* *}$ \\
\hline $\begin{array}{l}\text { Visual acuity, } n(\%) \\
\text { Mild-no impairment } \\
\text { Moderate VI } \\
\text { Severe VI } \\
\text { Blind-LP } \\
\text { Blind-NLP } \\
\end{array}$ & $\begin{aligned} & 12(18.5) \\
& 17(26.2) \\
& 18(27.7) \\
& 15(23.1) \\
& 3(4.6) \\
&\end{aligned}$ & $\begin{array}{c}2(12.5) \\
5(31.3) \\
3(18.8) \\
4(25) \\
2(12.5) \\
\end{array}$ & $\begin{aligned} & 10(20.4) \\
& 12(24.5) \\
& 15(30.6) \\
& 11(22.4) \\
& 1(2.0) \\
&\end{aligned}$ & $0.32^{* *}$ \\
\hline $\begin{array}{l}\text { RAPD, n(\%) } \\
1+ \\
2+ \\
3+ \\
4+ \\
\text { Not reliable } \\
\end{array}$ & $\begin{aligned} 2 & (3.1) \\
19 & (29.2) \\
29 & (44.6) \\
3 & (4.6) \\
12 & (18.5)\end{aligned}$ & $\begin{array}{ll}1 & (6.25) \\
6 & (37.5) \\
6 & (37.5) \\
2 & (12.5) \\
1 & (6.25)\end{array}$ & $\begin{aligned} 1 & (2.04) \\
13 & (26.5) \\
22 & (44.9) \\
2 & (4.1) \\
11 & (22.46)\end{aligned}$ & $0.78^{* *}$ \\
\hline $\begin{array}{l}\text { Disc swelling, } n \text { (\%) } \\
\text { Positive } \\
\text { Negative }\end{array}$ & $\begin{array}{l}12(18.5) \\
53(81.5)\end{array}$ & $\begin{array}{c}3(18.8) \\
13(81.2)\end{array}$ & $\begin{array}{c}9(18.4) \\
40(84.6)\end{array}$ & $0.97^{* *}$ \\
\hline
\end{tabular}

${ }^{*}$ Independent samples $t$-test. ${ }^{* *}$ Chi-square test. AON: acute optic neuritis; VI: visual impairment; LP: light perception; NLP: no light perception; RAPD: relative afferent pupil defect.

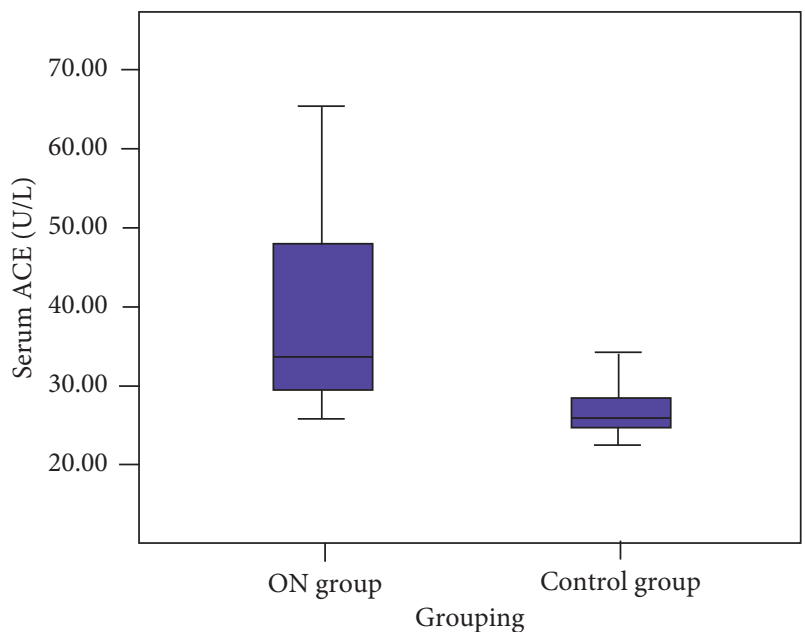

FIGURE 1: Median serum ACE level was higher in the ON patients than in the control group.

statistically significant correlation was found between LogMAR VA and serum ACE level of the patients $(\rho=-0.40$ and $P=0.001$ ).

\section{Discussion}

Our study indicated that the mean serum ACE level was significantly increased in idiopathic acute ON patients than in healthy subjects.

In the current study, we investigated the serum ACE activity in idiopathic acute $\mathrm{ON}$ based on these hypothesis in which $\mathrm{ON}$ is considered as an immunologically mediated

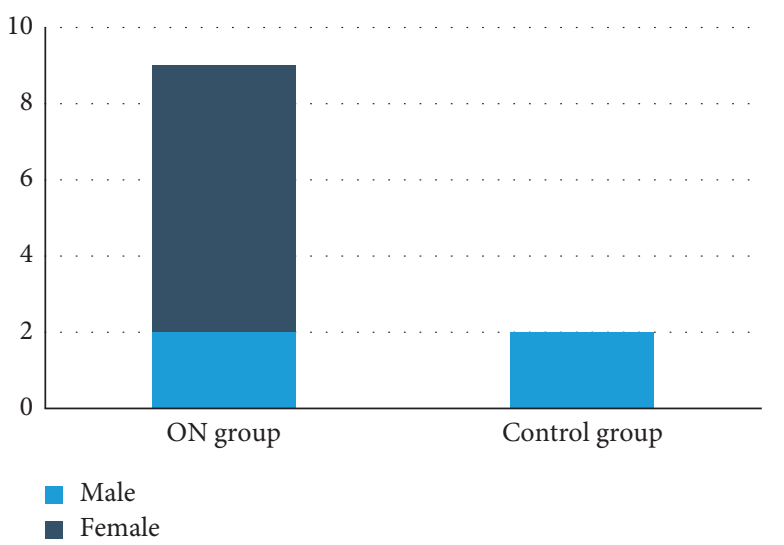

FIGURE 2: Distribution of high level of serum ACE in both groups.

inflammatory central nervous system disease and ACE activity may be involved in its pathogenesis [18].

In a mouse model of ON, Guo et al. [19] asserted that the RAS regulated neurodegeneration in ON. They noticed an association in astrocytes between RAS and the innate immune system in a mouse model of ON [19]. Similarly, the current data in idiopathic acute ON patients indicate a possible role of RAS and ACE activity in ON. These results can highlight the possible role of ACE in the pathogenesis of $\mathrm{ON}$, and it may be helpful to use ACE as a serologic marker for disease activity in ON. With this concept, measurement of serum ACE levels can be considered a screening test in the initial evaluation of patients suspected of having $\mathrm{ON}$, but there is normal vision and mild visual impairment in the first presentation. 
TABLE 2: Correlation of the clinical characteristics of idiopathic acute $\mathrm{ON}$ patients with serum ACE level.

\begin{tabular}{lcc}
\hline Variable & $\begin{array}{c}\text { Serum ACE; } \\
\text { Median (min-max) }\end{array}$ & $P$ value \\
\hline Sex & $33.50(29.1-540.0)$ & $0.77^{*}$ \\
Male & $33.50(25.9-509.6)$ & \\
Female & $32.90(26.90-216.70)$ & $0.29^{*}$ \\
\hline Affected eye & $36.20(25.9-540.0)$ & \\
Right & $51.30(27.20-540)$ & \\
Left & $33.30(26.90-220.80)$ & \\
\hline Visual acuity classification & $31.75(28.30-176.30)$ & $0.03^{* *}$ \\
Mild-No impairment & $35.70(25.90-509.60)$ & \\
Moderate VI & $29.10(28.30-30.60)$ & \\
Severe VI & & \\
Blind-LP & $283.45(26.9-540.0)$ & \\
Blind-NLP & $33.3(27.2-188.1)$ & \\
\hline RAPD & $32.55(25.9-220.8)$ & $0.85^{* *}$ \\
1+ & $29.85(28.7-46.1)$ & \\
2+ & $32.2(25.9-540.0)$ & \\
3+ & & \\
$4+$ & $37.50(27.2-53.4)$ & $0.93^{*}$ \\
Not reliable & $33.1(25.9-540.0)$ & \\
\hline Disc swelling &
\end{tabular}

${ }^{*}$ Mann-Whitney test. ${ }^{* *}$ Kruskal-Wallis test. ON: optic neuritis; VI: visual impairment; LP: light perception; NLP: no light perception; RAPD: relative afferent pupil defect.

RAS system hyperactivation has been demonstrated to be involved in inflammatory responses of eyes $[20,21]$. The exact mechanism responsible for the increase of the serum $\mathrm{ACE}$ activity in $\mathrm{ON}$ is unclear. There was the evidence that myelin induced the macrophages to produce ACE, suggesting a potential mechanism of ACE induction during the inflammatory process in CNS $[12,16,21]$. A previous study indicated that inhibition of ACE activity could suppress oxygen radicals and cytokine-mediating damage in MS $[22,23]$. Future studies may identify inhibition of ACE activity in ON improvement. Furthermore, it has been shown that steroids modulate the ACE activity [24, 25], and it would be probable that one of the possible mechanisms of the dramatic response of $\mathrm{ON}$ to the systemic corticosteroid is due to alternation of ACE activity.

Information about the possible role of ACE in the pathogenesis of ocular diseases is limited. Increased serum ACE activity has been reported, particularly in uveitis associated with sarcoidosis, as well as infectious uveitis such as recurrent toxoplasmic and toxocaral iridocyclitis, chorioretinitis, and Vogt-Koyanagi-Harada's diseases [26, 27]. There are correlations between serum levels of inflammatory chemokines and cytokines with serum ACE activities [28, 29].

We noted that the serum ACE level was higher in patients with better VA, so theoretically, high serum level of ACE can correlate initiation of inflammatory process that could be an initial screening marker for detection of suspected idiopathic acute $\mathrm{ON}$.

In our study, despite the lack of any significant difference between genders in the ACE level in ON patients, the level of serum ACE was lower in female patients compatible with the previous low level of ACE in females due to synthesis of ACE in the Leydig cells of the testis.

Although our study had several limitations, this was the first assay investigating the relationship between the serum ACE level and new cases of idiopathic acute ON.

Our limitations were a lack of further follow-up whether case of ON completely meets the criteria for diagnosis of demyelinating disorders of CNS, including MS or NMO. Another limitation of this study was the lack of evaluating the level of other RAS components for each participant.

\section{Conclusion}

The current study results indicated that the serum level of ACE appeared to be significantly higher in acute $\mathrm{ON}$ than in normal controls. Further experimental and clinical studies are required to elucidate any possible role of RAS components in $\mathrm{ON}$.

\section{Data Availability}

The data used to support the findings of this study are available from the corresponding author upon request.

\section{Conflicts of Interest}

The authors declare that there are no conflicts of interest.

\section{References}

[1] A. Abel, M. S. McClelland, and M. S. Lee, "Critical review: typical and atypical optic neuritis," Survey of Ophthalmology, vol. 64, no. 6, pp. 770-779, 2019.

[2] K. Soelberg, S. Jarius, H. Skejoe et al., "A population-based prospective study of optic neuritis," Multiple Sclerosis Journal, vol. 23, no. 14, pp. 1893-1901, 2017.

[3] R. Deschamps, A. Lecler, C. Lamirel et al., "Etiologies of acute demyelinating optic neuritis: an observational study of 110 patients," European Journal of Neurology, vol. 24, no. 6, pp. 875-879, 2017.

[4] M. H. Levin, "Demyelinating optic neuritis and its subtypes," International Ophthalmology Clinics, vol. 59, no. 3, pp. 23-37, 2019.

[5] L. J. Balcer, "Optic neuritis," New England Journal of Medicine, vol. 354, no. 12, pp. 1273-1280, 2006.

[6] J. Lieberman, "Elevation of serum angiotension-convertingenzyme (ACE) level in sarcoidosis," The American Journal of Medicine, vol. 59, no. 3, pp. 365-372, 1975.

[7] M. Goto, M. Sasano, M. Fuzisawa, K. Okabe, and K. Nishizawa, "Constitutive production of angiotensin converting enzyme from rheumatoid nodule cells under serum free conditions," Annals of the Rheumatic Diseases, vol. 51, no. 6, pp. 741-742, 1992.

[8] H. Schweisfurth, S. Schiöberg-Schiegnitz, B. Kuhn, and B. Parusel, "Angiotensin I converting enzyme in cerebrospinal fluid of patients with neurological diseases," Klinische Wochenschrift, vol. 65, no. 20, pp. 955-958, 1987.

[9] J. Culman, A. Blume, T. Gohlke, and T. Unger, "The reninangiotensin system in the brain: possible therapeutic implications for AT1-receptor blockers," Journal of Human Hypertension, vol. 16, no. S3, pp. S64-S70, 2002. 
[10] M. Mogi, J.-M. Li, J. Iwanami et al., “Angiotensin II type-2 receptor stimulation prevents neural damage by transcriptional activation of methyl methanesulfonate sensitive 2," Hypertension, vol. 48, no. 1, pp. 141-148, 2006.

[11] J.-M. Li, M. Mogi, K. Tsukuda et al., "Angiotensin II-induced neural differentiation via angiotensin II type 2 (AT2) receptor-MMS2 cascade involving interaction between AT2Receptor-interacting protein and src homology 2 domain-containing protein-tyrosine phosphatase 1," Molecular Endocrinology, vol. 21, no. 2, pp. 499-511, 2007.

[12] J. Stegbauer, D.-H. Lee, S. Seubert et al., "Role of the reninangiotensin system in autoimmune inflammation of the central nervous system," Proceedings of the National Academy of Sciences, vol. 106, no. 35, pp. 14942-14947, 2009.

[13] M. Garg, S. G. Royce, C. Tikellis et al., "Imbalance of the renin-angiotensin system may contribute to inflammation and fibrosis in IBD: a novel therapeutic target?" Gut, 2019.

[14] R. Ranjbar, M. Shafiee, A. Hesari, G. A. Ferns, F. Ghasemi, and A. Avan, "The potential therapeutic use of renin-angiotensin system inhibitors in the treatment of inflammatory diseases," Journal of Cellular Physiology, vol. 234, no. 3, pp. 2277-2295, 2019.

[15] M. Platten, S. Youssef, E. M. Hur et al., "Blocking angiotensinconverting enzyme induces potent regulatory $\mathrm{T}$ cells and modulates TH1-and TH17-mediated autoimmunity," Proceedings of the National Academy of Sciences, vol. 106, no. 35, pp. 14948-14953, 2009.

[16] C. S. Constantinescu, D. B. P. Goodman, R. I. Grossman, J. A. Mannon, and J. A. Cohen, "Serum angiotensin-converting enzyme in multiple sclerosis," Archives of Neurology, vol. 54, no. 8, pp. 1012-1015, 1997.

[17] R. A. Luke, B. J. Stern, C. J. Krumholz, and C. J. Johns, "Neurosarcoidosis: the long-term clinical course," Neurology, vol. 37, no. 3, p. 461, 1987.

[18] M. R. W. Ehlers and J. F. Riordan, "Angiotensin-converting enzyme: new concepts concerning its biological role," Biochemistry, vol. 28, no. 13, pp. 5311-5318, 1989.

[19] X. Guo, K. Namekata, A. Kimura, T. Harada, and T. Harada, "The renin-angiotensin system regulates neurodegeneration in a mouse model of optic neuritis," The American Journal of Pathology, vol. 187, no. 12, pp. 2876-2885, 2017.

[20] A. Miyazaki, N. Kitaichi, K. Ohgami et al., "Anti-inflammatory effect of angiotensin type 1 receptor antagonist on endotoxin-induced uveitis in rats," Graefe's Archive for Clinical and Experimental Ophthalmology, vol. 246, no. 5, pp. 747-757, 2008.

[21] T. Kurihara, Y. Ozawa, S. Ishida, H. Okano, and K. Tsubota, "Renin-Angiotensin system hyperactivation can induce inflammation and retinal neural dysfunction," InternationalJournal of Inflammation, vol. 2012, Article ID 581695, 14 pages, 2012.

[22] S. P. Andreoli, "Captopril scavenges hydrogen peroxide and reduces, but does not eliminate, oxidant-induced cell injury," American Journal of Physiology-Renal Physiology, vol. 264, no. 1, pp. F120-F127, 1993.

[23] R. Schindler, K.-M. Dinarello, and K. M. Koch, "Angiotensinconverting-enzyme inhibitors suppress synthesis of tumour necrosis factor and interleukin 1 by human peripheral blood mononuclear cells," Cytokine, vol. 7, no. 6, pp. 526-533, 1995.

[24] H. Yotsumoto, "Longitudinal observations of serum angiotensin-converting enzyme activity in sarcoidosis with and without treatment," Chest, vol. 82, no. 5, pp. 556-559, 1982.

[25] L. Derveaux, M. Demedts, P. Lijnen, and A. Amery, "Plasma angiotensin converting enzyme in the diagnosis and monitoring of disease activity in sarcoidosis," European Journal of Respiratory Diseases, vol. 64, no. 64, pp. 197-206, 1983.

[26] M. Mulak, M. Misiuk-Hojlo, and M. Slowik, "The behavior of angiotensin-converting enzyme in patients with uveitis," Klinika Oczna, vol. 101, pp. 5-8, 1999.

[27] R. Fukami, S. Ohba, K. Ishida, S. Nakamura, M. Konno, and S. Ohno, "Serum adenosine deaminase and angiotensin converting enzyme activity in patients with endogenous uveitis," Nippon Ganka Gakkai Zasshi, vol. 98, pp. 287-292, 1994.

[28] M. Takeuchi, K. Oh-i, J. Suzuki et al., "Elevated serum levels of CXCL9/monokine induced by interferon- $\gamma$ and CXCL10/ interferon- $\gamma$-inducible protein-10 in ocular sarcoidosis," Investigative Opthalmology \& Visual Science, vol. 47, no. 3, pp. 1063-1068, 2006.

[29] G. Trinchieri, "Interleukin-12: a cytokine produced by antigenpresenting cells with immunoregulatory functions in the generation of T-helper cells type 1 and cytotoxic lymphocytes," Blood, vol. 84, no. 12, pp. 4008-4027, 1994. 